brain. A stereotaxic atlas of the forebrain and lower parts of the brain stem. Baltimore: Williams \& Wilkins, 1963.

PELLEGRINO, L. J., \& CUSHMAN, A. J. A stereotaxic atlas of the rat brain. New York: Appleton-Century-Crofts, 1967.

\section{A fool-proof hurdle for two-way shuttlebox*}

\section{RAYMOND DUCHARME FRANCO LEPORE and \\ LUC GRANGER}

Université de Montréal

Montréal, Québec, Canada

The two-way shuttlebox has been extensively used for the avoidance conditioning of rats. Yet, unlike other common laboratory apparatus, such as the Skinner box, few attempts (Baum, 1965; Brush \& Knaff, 1959) have been made to automate the shuttlebox to the same degree of sophistication. The apparatus presented here solves two problems often encountered in avoidance conditioning (Bitterman, 1966): fence straddling and partial crossing. They are rendered impossible by using a moving Plexiglas cylinder as a barrier instead of a rigid partition.

The revolving Plexiglas cylinder, $20 \mathrm{~cm}$ long, $5 \mathrm{~cm}$ in diam, and $7 \mathrm{~cm}$

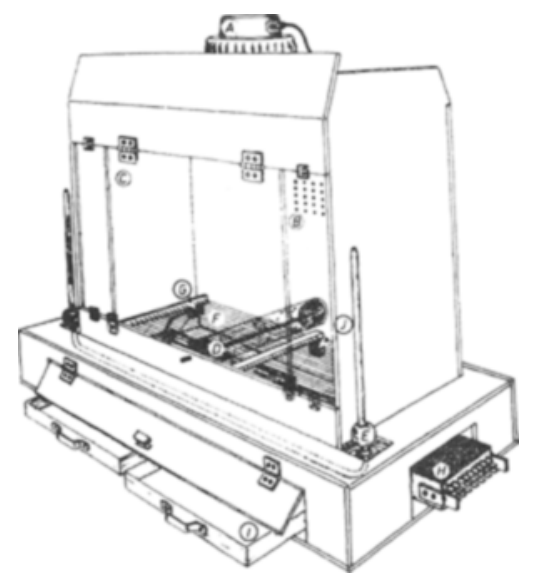

Fig. 1. Automated two-way shuttlebox for the avoidance conditioning of rats. ( $A=$ ventilating fan; $B=C S$ speaker inlet; $C=$ transparent door; $D=$ revolving cylindrical barrier; $\mathbf{E}=$ mercury balance and selector switch; $F=$ metal floors; $G=$ stop microswitch; $\mathrm{H}=$ outlet to shock scrambler; $I=$ removable trays; $j=$ fulcrum of pivoting floor.)

*Development of this apparatus was aided by Grant APA-215 from the National Research Council of Canada. high, separates the box into two equal compartments (Fig. 1). The fact that the cylinder can rotate about its axis makes it impossible for the animal to straddle the fence. If the animal tries to do so, his weight on the cylinder rotates the device. Partial crossing is also eliminated by the diameter of the cylinder and its height in the box. It is impossible for a normal rat to lie crosswise over the cylinder, putting one set of paws in the first compartment and the other in the second.

An apparatus equipped with this kind of hurdle has been used for various experiments to condition approximately 150 rats. Not once was the intervention of the $E$ required during training, nor did any problem develop in the apparatus. This kind of cylinder, which proved very effective, could easily be adapted to any home-made or commercial type of shuttlebox.

\section{REFERENCES}

BAUM, M. An automated apparatus for the avoidance training of rats. Psychological Reports, 1965, 16, 1205-1211.

BITTERMAN, M. E. Animal leaming. In J. B. Sidowski (Ed.), Experimental methods and instrumentation in psychology. New York: McGraw-Hill, 1966. Pp. 451-484.

BRUSH, F, R \& KNAFF, P. R. A device for detecting and controlling automatic programming of avoidance conditioning in a shuttle-box. American Journal of Psychology, 1959, 72, 275-278.

\section{Modification of an autotransformer to present a titrated aversive schedule}

\author{
KARL W. SCHWEICKARDT \\ HAROLD D. TAYLOR, JR., \\ and DENNIS R. COOPER \\ Dynalectron Corporation \\ Holloman AFB \\ New Mexico 88330 \\ QUENTIN R. REGESTEIN \\ Peter Bent Brigham Hospital \\ Boston, Massachusetts 02115 \\ and \\ WILLIAM J. JACKSON \\ University of South Florida \\ Tampa, Florida 33620
}

We recently developed a reliable, accurate, relatively inexpensive apparatus for presenting a titrating aversive schedule. Although there are numerous variations of the titrating schedule, it always involves increasing the intensity of an aversive stimulus as a function of selected time intervals. The chosen operant response reduces shock intensity by a given amount (Weiss \& Laties, 1961). Our particular variation involved a discrete-trials contingency in which the Ss were shocked every $7 \mathrm{sec}$ with only the first level press of a given increment-to-increment interval effective in reducing the intensity of the next shock.

Our apparatus was the endpoint of a series of modifications which originally began with a replication of the apparatus described by Weiss and Laties (1961). This Weiss and Laties apparatus coupled a Grason-Stadler recording attenuator to the intensity control shaft of a shocker. Our replica of this apparatus allowed at least $3 \%$ and up to $7 \%$ hysteresis, depending upon different methods of coupling. Since the goal of our particular project was to provide shock increments of $5 \%$, this hysteresis involved an unacceptable amount of error.

Next, we coupled a bidirectional stepping motor to the intensity control shaft of the shocker. This method was plagued with overthrow and insufficient feedback to the drive and control circuitry for error correction and detection. The stepper adequately turned the shaft, but the inertia of the rotation armature caused an override of the stepper's internal detents. Externally mounted adjustable-tension detent springs were installed and found to prevent overthrow effectively when adjusted to approximately the same force required to stop the stepper. This method was abandoned.

These failures convinced us to break with previous electromechanical design and to develop a shocker containing a variable autotransformer as the intensity control. Six BRS SG-002 shockers were used, although any constant wattage shocker would do as well.

Disassembly of the transformer is a simple task, but care should be taken to protect the brush which is loosened early in the process. Since the increment between shock intensities is a function of the number of turns between taps, the number of windings must be as equal as possible. Decrements were within $0.5 \%$ in the most variant case, while increments were within $0.2 \%$ of the desired $5.0 \%$.

Verifications of the accuracy of the six shocker outputs were accomplished by connecting all six shockers to a large regulated ac power supply. Standard calibration techniques were used, with a $4.0-\mathrm{K}$-ohm resistor used to simulate the resistance of the research Ss. The instruments used to measure the shocker output were a Hewlett-Packard Dymec Model 2410-B ac-to-ohms converter and a Hewlett-Packard Dymec Model 2401-C Integrating Digital Voltmeter. The results of these measurements showed very good agreement between range overlay, current regulation, and shock intensity period. Subsequent maintenance checks were made with 